\title{
PM100117 and PM100118, new antitumor macrolides produced by a marine Streptomyces caniferus GUA-06-05-006A
}

\author{
Marta Pérez, Carmen Schleissner, Rogelio Fernández, Pilar Rodríguez, Fernando Reyes ${ }^{1}$, Paz Zuñiga, \\ Fernando de la Calle and Carmen Cuevas \\ Two new bioactive polyhydroxyl macrolide lactones PM100117 (1) and PM100118 (2) were isolated from the culture \\ broth of the marine-derived Streptomyces caniferus GUA-06-05-006A. Their structures were elucidated by a combination of \\ spectroscopic methods, mainly one-dimensional and 2D NMR and HRESI-MS. They consist of 36-membered macrolides with a \\ side chain containing three deoxy sugars and a 1,4-naphthoquinone chromophore. Compounds 1 and 2 displayed potent \\ cytotoxicity against three human tumor cell lines with $\mathrm{Gl}_{50}$ values in the micromolar range, as well as slight antifungal activity \\ against Candida albicans ATCC10231. In addition, both compounds alter the plasma membrane of tumor cells, inducing loss of \\ membrane integrity and subsequent cell permeabilization leading to a fast and dramatic necrotic cell death. \\ The Journal of Antibiotics (2016) 69, 388-394; doi:10.1038/ja.2015.121; published online 9 December 2015
}

\section{INTRODUCTION}

Many macrolides with unique and diverse structures as well as various biological activities have been isolated from microorganisms. Thus, 14-, 15- and 16-membered macrolides have been discovered and found to have interesting antibiotic, antifungal and immunosuppressive properties with some being used to treat infections. ${ }^{1}$ Larger macrolides, often containing tetrahydropyran rings and sugar residues, have exhibited other interesting biological properties such as antitumor activities. Specifically, the recently described 32-membered macrolide, the novonestmycins, closely related to the notonesomycins, have shown strong antifungal and cytotoxic activity. ${ }^{2}$ Copiamycins, ${ }^{3}$ langkolide ${ }^{4}$ and brasilinolides, ${ }^{5}$ provide other examples of 32-membered macrocyclic lactones with a six-membered hemiketal ring that have shown antifungal, antibiotic and immunosuppressive activities.

A further example of an even larger macrolide is GT- $35,{ }^{6}$ which emerged as a promising drug lead for both antifungal and antitumor therapies. This compound contains a 36-membered macrocyclic lactone with a tetrahydropyran ring as well as an epoxide, two deoxy sugars and a chromophore system. The structurally related metabolites, axenomycin, ${ }^{7}$ liposidolide $\mathrm{A}^{8}$ and the polaramycins ${ }^{9}$ have also been found in Streptomyces cultures and reported as new antifungal and antibiotic macrolides.

In the course of our screening for antitumor compounds from marine cultivable bacteria, two new bioactive polyhydroxyl macrolide lactones PM100117 (1) and PM100118 (2), were isolated from the culture broth of the marine-derived Streptomyces caniferus
GUA-06-05-006A. 1 and 2 display evident structural similarities to the closely related macrolide GT-35. Spectroscopic studies showed PM100117 and PM100118 to have complex structures containing a macrocyclic lactone, three deoxy sugars and a 1,4-naphthoquinone chromophore. In this paper, we report the bacteria isolation, culture, extraction, structure elucidation, physicochemical properties and biological activities of these compounds.

\section{RESULTS}

The extract of fermented broth of Streptomyces caniferus GUA-06-05006A was fractionated by repeated chromatography to yield compounds 1 and 2 (Figure 1). Their structures were elucidated on the basis of spectroscopic methods.

\section{Physicochemical properties}

PM100117 and PM100118 were isolated as reddish and pale yellow powders, respectively. Both compounds were readily soluble in methanol and acetonitrile and partially soluble in chloroform. The molecular formulae of $\mathbf{1}$ and $\mathbf{2}$ were established as $\mathrm{C}_{82} \mathrm{H}_{130} \mathrm{O}_{29}$ and $\mathrm{C}_{82} \mathrm{H}_{130} \mathrm{O}_{28}$ on the basis of HRESI-TOF MS spectra data $(\mathrm{m} / \mathrm{z}$ 1601.8621 $(\mathrm{M}+\mathrm{Na})^{+}$, calcd. 1601.8590 and $1585.8746(\mathrm{M}+\mathrm{Na})^{+}$, calcd. 1585.8641), respectively. The IR spectra indicated the presence of free hydroxyls (3399 and $3396 \mathrm{~cm}^{-1}$ for $\mathbf{1}$ and 2, respectively), acetal groups (1054 and $1083 \mathrm{~cm}^{-1}$ for 1 and 2, respectively) and conjugated ester groups (1720 and $1729 \mathrm{~cm}^{-1}$ for $\mathbf{1}$ and $\mathbf{2}$, respectively). The presence of a naphthoquinone system was also indicated by the UV $\left(\lambda_{\max } 249\right.$ and $345 \mathrm{~nm}$ ) spectra (Supplementary Table S3).

Drug Discovery Area, PharmaMar S.A, Colmenar Viejo, Madrid, Spain

${ }^{1}$ Current address: Fundación Medina, Granada, Spain

Correspondence: Dr M Pérez, Natural Product, Pharmamar, Avenida de los reyes, 1, Pol. In. La mina, Colmenar Viejo, 28770 Madrid, Spain.

E-mail: mperez@pharmamar.com

Received 2 July 2015; revised 15 October 2015; accepted 28 October 2015; published online 9 December 2015 


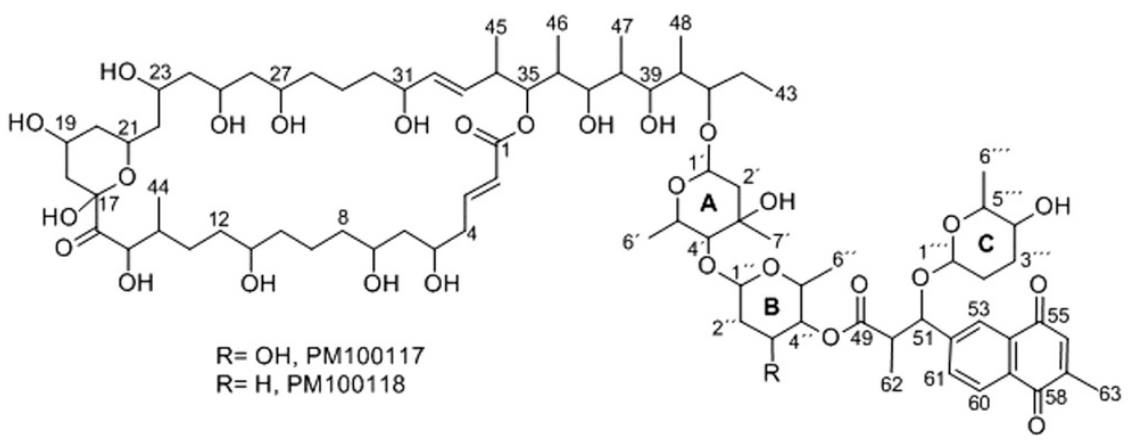

Figure 1 Structures of PM100117 and PM100118.

Table $1{ }^{1} \mathrm{H}$ and ${ }^{13} \mathrm{C}$ NMR $(500 / 125 \mathrm{MHz})$ data of compounds 1 and $2\left(\mathrm{CD}_{3} \mathrm{OD}\right)$

\begin{tabular}{|c|c|c|c|c|c|c|c|c|c|}
\hline$N^{o}$ & $\begin{array}{c}1 \\
{ }^{1} H, \text { mult, } \mathrm{J}=H z\end{array}$ & $\begin{array}{c}1 \\
{ }^{13} \mathrm{C}\end{array}$ & $\begin{array}{c}2 \\
{ }^{1} H, \text { mult, } \mathrm{J}=H z\end{array}$ & ${ }^{2}$ & $N^{o}$ & $\begin{array}{c}1 \\
{ }^{1} \mathrm{H}, \text { mult, } \mathrm{J}=\mathrm{Hz}\end{array}$ & $\begin{array}{c}1 \\
{ }^{13} \mathrm{C}\end{array}$ & 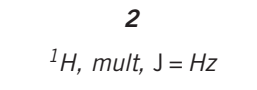 & ${ }^{2}$ \\
\hline 1 & & 168.5 & & 168.5 & 42 & $1.62, \mathrm{~m} ; 1.39, \mathrm{~m}$ & 22.8 & $1.62, \mathrm{~m} ; 1.40, \mathrm{~m}$ & 23.0 \\
\hline 3 & 7.02, ddd, $15.0,7.3,7.3$ & 147.9 & 7.03, m & 147.9 & 44 & $0.78, d, 6.9$ & 13.6 & $0.79, \mathrm{~d}, 6.9,3 \mathrm{H}$ & 13.6 \\
\hline 4 & $2.45, \mathrm{~m} ; 2.35, \mathrm{~m}$ & 41.4 & $2.45, \mathrm{~m} ; 2.35, \mathrm{~m}$ & 41.2 & 45 & $1.02, d, 6.8$ & 17.3 & $1.03, \mathrm{~d}, 6.7,3 \mathrm{H}$ & 17.3 \\
\hline 5 & $3.92, \mathrm{~m}$ & 70.2 & $3.93, \mathrm{~m}$ & 70.1 & 46 & $0.89, \mathrm{~d}, 6.9$ & 9.7 & $0.90, \mathrm{~d}, 6.9,3 \mathrm{H}$ & 9.7 \\
\hline 8 & $1.38-1.51, \mathrm{~m}$ & 38.7 & $1.38-1.51, \mathrm{~m}$ & 38.7 & $1^{\prime}$ & $5.01, d, 4.1$ & 96.5 & $5.03, d, 3.5$ & 96.4 \\
\hline 9 & $1.62, \mathrm{~m} ; 1.40, \mathrm{~m}$ & 23.0 & $1.62, \mathrm{~m} ; 1.40, \mathrm{~m}$ & 23.0 & $2^{\prime}$ & $1.98, \mathrm{~m} ; 1.61, \mathrm{~m}$ & 38.1 & $1.98, \mathrm{~m} ; 1.61, \mathrm{~m}, 2 \mathrm{H}$ & 38.1 \\
\hline 10 & $1.38-1.51, \mathrm{~m}$ & 38.6 & $1.38-1.51, \mathrm{~m}$ & 38.6 & $3^{\prime}$ & - & 71.0 & - & 71.2 \\
\hline 11 & $3.51, \mathrm{~m}$ & 72.9 & $3.52, \mathrm{~m}$ & 72.9 & $4^{\prime}$ & 3.26 , br s & 83.4 & 3.28 , br s & 83.8 \\
\hline 12 & $1.38-1.51, \mathrm{~m}$ & 36.2 & $1.38-1.51, \mathrm{~m}$ & 36.2 & $5^{\prime}$ & 4.48. br q, 6.4 & 64.9 & 4.49. br q, 6.7 & 65.2 \\
\hline 13 & $1.66, \mathrm{~m} ; 1.30, \mathrm{~m}$ & 31.9 & $1.67, \mathrm{~m} ; 1.31, \mathrm{~m}$ & 31.9 & $6^{\prime}$ & $1.21, \mathrm{~d}, 6.7$ & 17.7 & $1.20, \mathrm{~d}, 6.7,3 \mathrm{H}$ & 17.7 \\
\hline 17 & - & 99.5 & - & 99.4 & $3^{\prime \prime}$ & $3.84, \mathrm{~m}$ & 66.6 & $2.15, \mathrm{~m} ; 1.75, \mathrm{~m}$ & 23.9 \\
\hline 18 & $2.07, \mathrm{dd}, 12.8,4.7 ; 1.34, \mathrm{~m}$ & 41.2 & $2.08, \mathrm{~m} ; 1.34, \mathrm{~m}$ & 41.2 & $4^{\prime \prime}$ & $4.80, \mathrm{dd}, 4.5,2.4$ & 75.4 & $4.93, \mathrm{~m}$ & 71.1 \\
\hline 19 & $4.07, \mathrm{~m}$ & 65.0 & $4.05, \mathrm{~m}$ & 64.9 & $5^{\prime \prime}$ & $4.46, \mathrm{~m}$ & 64.4 & $4.22, \mathrm{dq}, 6.3,1.4$ & 67.5 \\
\hline 20 & $1.94, \mathrm{~m} ; 1.22, \mathrm{~m}$ & 42.1 & $1.95, \mathrm{~m} ; 1.22, \mathrm{~m}$ & 42.1 & $6^{\prime \prime}$ & $1.14, d, 6.7$ & 16.4 & $1.12, \mathrm{~d}, 6.6,3 \mathrm{H}$ & 17.5 \\
\hline 21 & $4.20, \mathrm{~m}$ & 67.8 & $4.19, \mathrm{~m}$ & 67.8 & 49 & - & 175.6 & - & 175.7 \\
\hline 22 & $1.63, \mathrm{~m}$ & 46.4 & $1.63, \mathrm{~m}, 2 \mathrm{H}$ & 46.4 & 50 & $2.98, \mathrm{dq}, 9.8,7.1$ & 48.3 & $2.99, \mathrm{dq}, 9.7,7.2$ & 48.2 \\
\hline 23 & 4.07, m & 65.5 & $4.05, \mathrm{~m}$ & 65.5 & 51 & $4.78, \mathrm{~d}, 10.0$ & 84.0 & $4.80, d, 9.7$ & 84.0 \\
\hline 24 & $1.57, \mathrm{~m}$ & 46.0 & $1.57, \mathrm{~m}, 2 \mathrm{H}$ & 46.0 & 52 & - & 148.6 & - & 148.6 \\
\hline 25 & $4.04, \mathrm{~m}$ & 68.3 & $4.05, \mathrm{~m}$ & 68.3 & 53 & $8.03, d, 1.7$ & 126.0 & $8.04, d, 1.7$ & 126.0 \\
\hline 26 & $1.53, \mathrm{~m}$ & 45.6 & $1.53, \mathrm{~m}, 2 \mathrm{H}$ & 45.6 & 54 & - & 133.5 & - & 133.5 \\
\hline 27 & $3.76, \mathrm{~m}$ & 71.5 & $3.78, \mathrm{~m}$ & 71.5 & 55 & - & 186.2 & - & 186.2 \\
\hline 36 & $1.97, \mathrm{~m}$ & 38.8 & $1.97, \mathrm{~m}$ & 38.8 & $1^{\prime \prime \prime}$ & $4.98, d, 4.2$ & 100.6 & $4.97, \mathrm{~d}, 2.0$ & 101.2 \\
\hline 37 & $3.37, \mathrm{br} d, 9.5$ & 78.5 & $3.38, \mathrm{br} d, 9.5$ & 78.6 & $2^{\prime \prime \prime}$ & $1.92, \mathrm{~m} ; 1.46, \mathrm{~m}$ & 24.5 & $1.93, \mathrm{~m} ; 1.45, \mathrm{~m}$ & 24.5 \\
\hline 38 & $1.81, \mathrm{~m}$ & 36.1 & $1.81, \mathrm{~m}$ & 36.1 & $3^{\prime \prime \prime}$ & $1.93, \mathrm{~m} ; 1.60, \mathrm{~m}$ & 26.7 & $1.93, \mathrm{~m} ; 1.61, \mathrm{~m}$ & 26.7 \\
\hline 39 & $3.51, \mathrm{~m}$ & 79.4 & $3.52, \mathrm{~m}$ & 79.5 & $4^{\prime \prime \prime}$ & 3.31 , br s & 67.8 & 3.33 , br s & 67.5 \\
\hline 40 & $2.00, \mathrm{~m}$ & 38.8 & $2.01, \mathrm{~m}$ & 38.8 & $5^{\prime \prime \prime}$ & 3.15 , br q, 6.8 & 68.3 & $3.18, \mathrm{dq}, 6.6,1.1$ & 68.3 \\
\hline 41 & $3.87, \mathrm{~m}$ & 80.7 & $3.88, m$ & 80.6 & $6^{\prime \prime \prime}$ & $0.46, d, 6.5$ & 16.7 & $0.47, \mathrm{~d}, 6.6,3 \mathrm{H}$ & 16.7 \\
\hline
\end{tabular}




\section{Structural elucidation}

The structures of $\mathbf{1}$ and $\mathbf{2}$ were elucidated by a combination of spectroscopic methods, mainly one-dimensional, 2D NMR (COSY, TOCSY, ROESY, HSQC, HMBC) in $\mathrm{CD}_{3} \mathrm{OD}$ at room temperature on a $500 \mathrm{MHz}$ instrument and HRESI-MS. The ${ }^{1} \mathrm{H}$ and ${ }^{13} \mathrm{C}$ NMR spectral data of both compounds are shown in Table 1. The structures consist on an aglycone macrolide system, a disaccharide moiety and a naphthoquinone unit with an appended deoxy-sugar as shown in Figure 1.

The ${ }^{13} \mathrm{C}$ NMR spectrum (Table 1) of the major compound PM100118 showed 82 signals assigned to 12 methyl, 21 methylene, 38 methyne and 11 quaternary carbons by HSQC experiments. The COSY spectrum revealed connectivities from $\mathrm{H}-2$ to $\mathrm{H}-15$ and from $\mathrm{H}-18$ to $\mathrm{H}-43$ with these two isolated spin systems being connected through $\mathrm{C}-17$ via a six-membered hemiketal ring as shown by a cross peak observed between $\mathrm{H}-18$ with $\mathrm{C}-16$ in the HMBC spectrum. In addition, a long-distance correlation between $\mathrm{H}-35$ and C-1 identified the precise linkage of the 36-membered macrolide ring system, establishing the ring closure across the lactone moiety.

Most of these signals were very similar to those reported for GT-35 (ref. 6) and the structure of the PM100118 aglycone backbone was further confirmed by HMBC correlations (Figure 2).

The geometries of the two double bonds of the macrolide moiety were both shown to be $E$ by the large coupling constants of $J_{2-3}=15.8 \mathrm{~Hz}$ and $J_{32-33}=15.5 \mathrm{~Hz}$, respectively, whereas the absolute configuration of the aglycone chiral centers remains to be determined. Additional support for this structure was provided by the presence of an ESI-MS fragment ion at $\mathrm{m} / \mathrm{z} 917$ originating from cleavage of the aglycone moiety.

In addition, the presence of the three deoxy sugars $\mathbf{A}, \mathbf{B}$ and $\mathbf{C}$ was evidenced by signals at 4.96, 4.97 and 5.03 p.p.m. in the ${ }^{1} \mathrm{H}$ NMR and by signals at $96.4,101.0$ and 101.2 p.p.m. in the ${ }^{13} \mathrm{C}$ NMR spectrum corresponding to the anomeric protons and carbons, respectively. The relative stereochemistry of these sugars was deduced from ROESY correlations and ${ }^{1} \mathrm{H}-{ }^{1} \mathrm{H}$ coupling constants as shown in Figure 2.
The sugar sequence of the 2,6-dideoxy-3-C-methyl-xylohexopyranoside $\mathrm{A}$ was constructed by ${ }^{1} \mathrm{H}$ spin networks from the anomeric proton $\mathrm{H}-1^{\prime}$ to $\mathrm{H}-2^{\prime}$ and from $\mathrm{H}-4^{\prime}$ to methyl $\mathrm{H}-6^{\prime}$, and $\mathrm{HMBC}$ from methyl $\mathrm{H}-7^{\prime}$ to $\mathrm{C}-3^{\prime}, \mathrm{C}-4^{\prime}$ and $\mathrm{C}-2^{\prime}$. The long-range $\mathrm{H}-\mathrm{C}$ coupling of the anomeric proton $\mathrm{H}-1^{\prime}$ with $\mathrm{C}-41$ in the $\mathrm{HMBC}$ experiment along with the small $J_{1^{\prime}-2^{\prime}}$ values suggested an $\alpha$-linkage between sugar A and C-41 of the side chain aglycone. Small vicinal proton coupling constants between $\mathrm{H}-4^{\prime}$ and $\mathrm{H}-5^{\prime}$ (Table 2) along with a cross peak between $\mathrm{H}-5^{\prime}$ and $\mathrm{H}-41$ and likewise between $\mathrm{H}-4^{\prime}$ and Me-7' but not with $\mathrm{H}-2^{\prime}{ }_{\mathrm{ax}}$ in the ROESY spectrum supported the axial $\mathrm{H}-5^{\prime}$-equatorial H-4'configuration. Furthermore, ROEs between Me- $6^{\prime}$ and $\mathrm{H}-\mathrm{1}^{\prime \prime}$ and between $\mathrm{Me}-\mathrm{7}^{\prime}$ and $\mathrm{H}-5^{\prime \prime}$ but not with $\mathrm{H}-5^{\prime}$, corroborated an equatorial position for both Me- 6 and Me-7 and established this sugar as $\alpha$-axenose.

The sugar sequence of the 2,3,6-trideoxy-hexoses $\mathbf{B}$ and $\mathbf{C}$ was constructed by ${ }^{1} \mathrm{H}$ spin networks from the anomeric proton $\mathrm{H}-1^{\prime \prime}$ $\left(\mathrm{H}-1^{\prime \prime \prime}\right)$ to methyl H-6" (H-6"' $)$. Both of these sugars were determined to be $\alpha$-rhodinoses, as a result of the ${ }^{1} \mathrm{H}$ and ${ }^{13} \mathrm{C}$ NMR chemical shifts and by analyzing the coupling constants between $\mathrm{H}-4^{\prime \prime}$ $\left(\mathrm{H}-4^{\prime \prime \prime}\right)$ and $\mathrm{H}-5^{\prime \prime}\left(\mathrm{H}-5^{\prime \prime \prime}\right)$. These constants were very small $\left(J_{4^{\prime \prime}-5^{\prime}}\right.$ , $=1.4 \mathrm{~Hz}$ and $J_{4^{\prime \prime \prime}-5^{\prime \prime \prime}}=1.1 \mathrm{~Hz}$, respectively) which discarded a diaxial orientation for these protons. In addition, the presence of a cross peak between $\mathrm{H}-5^{\prime \prime}\left(\mathrm{H}-5^{\prime \prime \prime}\right)$ and one of the $\mathrm{H}-3^{\prime \prime}\left(\mathrm{H}-3^{\prime \prime \prime}\right)$ and $\mathrm{Me}-\mathrm{7}^{\prime}$ in the ROESY spectrum showed that $\mathrm{H}-5^{\prime \prime}\left(\mathrm{H}-5^{\prime \prime \prime}\right)$ was in an axial position, thereby establishing an equatorial configuration for $\mathrm{H}-4^{\prime \prime}\left(\mathrm{H}-4^{\prime \prime \prime}\right)$. Finally, the small coupling constant values $(J \sim 2 \mathrm{~Hz})$ for the anomeric protons suggested an equatorial position for these protons and therefore $\alpha$-glycoside bonds. $\alpha$-Rhodinose is a constituent of several classes of natural products such as lactonamycin, ${ }^{10}$ and cirramycin F$1 .{ }^{11}$ Extensive similarities were found when comparing the chemical shifts and coupling constants of the $\mathbf{B}$ and $\mathbf{C}$ moieties with the values reported for the aforementioned $\alpha$-rhodinose containing antibiotics. ${ }^{10,11}$

The long-range $\mathrm{H}-\mathrm{C}$ coupling of the anomeric proton $\mathrm{H}-\mathrm{l}^{\prime \prime}$ with C- $4^{\prime}$ in the HMBC experiment suggested that sugar $\mathbf{B}$ was linked to
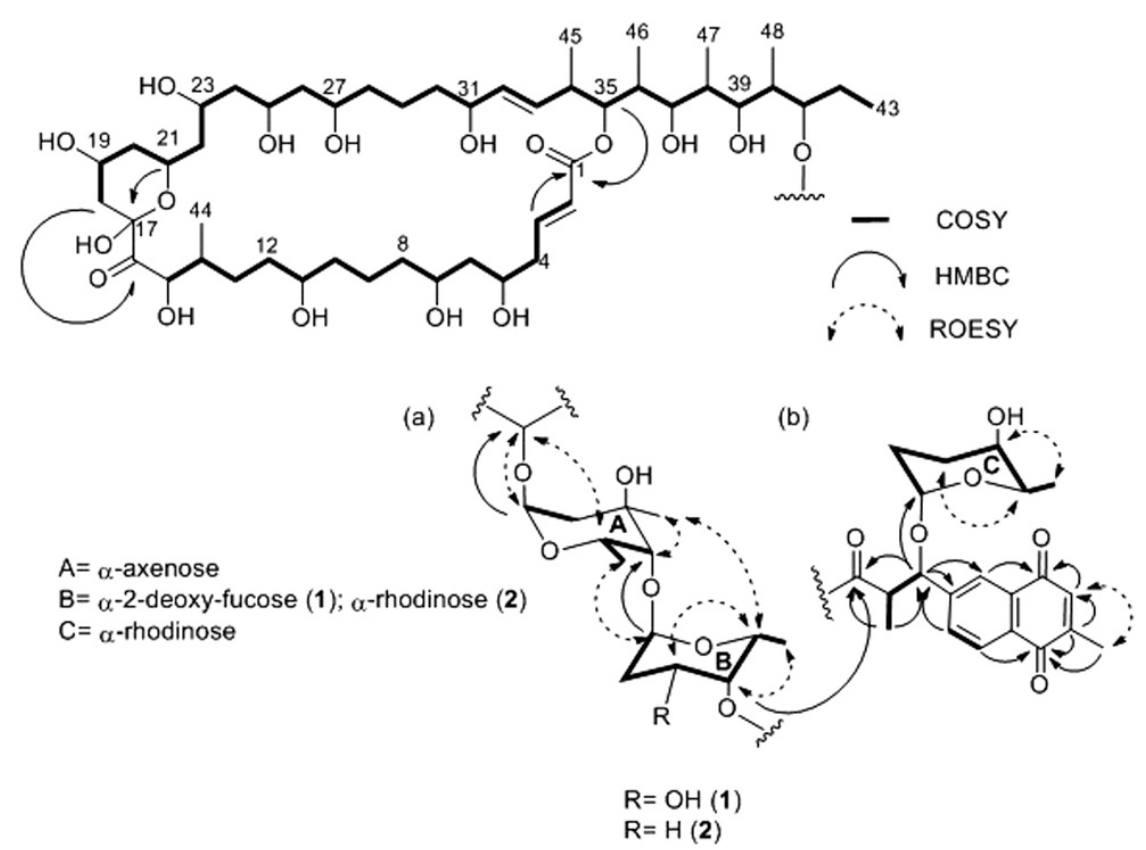

Figure 2 Selected 2D NMR correlations for the aglycone of $\mathbf{2}$ and ROESY correlations and relative stereochemistry for the (a) sugars $\mathbf{A}$ and $\mathbf{B}$ and (b) the naphthoquinone appended in 2. 
Table 2 Cytotoxic activity data ( $\mu \mathrm{M})$ of compounds 1 and 2.

\begin{tabular}{|c|c|c|c|}
\hline \multirow{2}{*}{ Compounds } & \multicolumn{3}{|c|}{ Cell line } \\
\hline & $\begin{array}{c}\text { Breast } \\
\text { MDA-MB-231 }\end{array}$ & Colon & $\begin{array}{c}\text { Lung } \\
\text { NSCLC A549 }\end{array}$ \\
\hline \multicolumn{4}{|l|}{ PM100117 } \\
\hline $\mathrm{Gl}_{50}$ & 1.5 & 1.9 & 0.70 \\
\hline TGI & 2.0 & 2.7 & 0.95 \\
\hline $\mathrm{LC}_{50}$ & 2.7 & 3.8 & 1.3 \\
\hline \multicolumn{4}{|l|}{ PM100118 } \\
\hline $\mathrm{Gl}_{50}$ & 1.7 & 9.2 & 0.83 \\
\hline TGI & 2.7 & 2.8 & 1.0 \\
\hline $\mathrm{LC}_{50}$ & 4.1 & 4.1 & 1.2 \\
\hline
\end{tabular}

the axenose unit through $\mathrm{C}-4^{\prime}$. In addition, long-distance correlations between $\mathrm{H}-4^{\prime \prime}$ and quaternary C-49 linked rhodinose B to the side portion containing a 1,4-naphthoquinone chromophore.

Part of the nature of the side portion attached to C- 4 " was deduced from detailed analysis of the ${ }^{1} \mathrm{H}-{ }^{1} \mathrm{H}$ COSY experiment revealing the connectivities from methyl H-62 to H-51, from H-60 to H-61 and, as mentioned above, from $\mathrm{H}-1^{\prime \prime \prime}$ to methyl $\mathrm{H}-6^{\prime \prime \prime}$. The remaining protons and carbons were assigned by HMBC and ROESY experiments. Long-range coupling from $\mathrm{H}-51$ to the ester carbonyl group C-49, methyl C-62, C-53 and C-61 and, in turn, from H-53 and $\mathrm{H}-60$ to quinone $\mathrm{C}-55$ and $\mathrm{C}-58$, respectively, along with correlations between H-56 with methyl C-63 and C-54 indicated the presence of the ester of a 2-methyl-1,4-naphthoquinone derivative in the structure of 2.

Finally, the connection of the remaining sugar moiety $\mathbf{C}$ was deduced from the HMBC correlation between the methyne $\mathrm{H}-51$ of the side portion and the anomeric $\mathrm{C}-1^{\prime \prime \prime}$ of the rhodomycin C completing the structure of PM100118. These results were also consistent with an ESI-MS fragment ion observed at $\mathrm{m} / \mathrm{z} 371$ and originating from loss of the side unit (ester cleavage) of the molecule.

Comparison of the spectroscopic data of $\mathbf{1}$ with that of $\mathbf{2}$ showed extensive similarities and the presence of the same aglycone and equivalent side portions in both substances.

The only notable differences were associated with sugar $\mathbf{B}$. Specifically the $3^{\prime \prime}$ position in compound $\mathbf{1}$ was shifted to lower field both in ${ }^{1} \mathrm{H}$ (from $\delta: 2.15 / 1.75$ to 3.84 p.p.m.) and ${ }^{13} \mathrm{C}$ (from $\delta: 23.9$ to 66.6 p.p.m.) NMR spectra, while integration of this signal revealed the presence of an oxymethyne instead of a methylene unit as in 2 . These observations confirmed compound $\mathbf{1}$ to be the hydroxylated analog of 2 at sugar B, consistent with the molecular formula and the presence of a single extra oxygen atom.

The sugar moiety B of PM100117 (1) was determined to be 2 -deoxy- $\alpha$-fucopyranose and the same as in the related structure brasilinolide, ${ }^{12}$ based on the ${ }^{1} \mathrm{H}$ and ${ }^{13} \mathrm{C}$ NMR chemical shifts and by analyzing the coupling constants of $\mathrm{H}-3^{\prime \prime}$ with $\mathrm{H}-4^{\prime \prime}$ and $\mathrm{H}-5^{\prime \prime}$. The observation of small coupling constants of $\mathrm{H}-3^{\prime \prime}$ with $\mathrm{H}-4^{\prime \prime}\left(J_{3^{\prime \prime}-4^{\prime}}\right.$ '= $4.5 \mathrm{~Hz})$ and with $\mathrm{H}-5^{\prime \prime}\left(J_{4^{\prime \prime}-5^{\prime \prime}}=2.4 \mathrm{~Hz}\right)$ and the observation of a cross peak between the $\mathrm{H}-3^{\prime \prime}$ and $\mathrm{H}-5^{\prime \prime}$ in the ROESY spectrum support the axial $\mathrm{H}-3^{\prime \prime}$ - equatorial $\mathrm{H}-4^{\prime \prime}$-axial $\mathrm{H}-5^{\prime \prime}$ configurations. The small coupling constant values $\left(J=4.4\right.$ and $4.4 \mathrm{~Hz}$ observed in ${ }^{1} \mathrm{H}$ $\mathrm{NMR}$ in $\mathrm{CD}_{3} \mathrm{CN}$ ) for the anomeric proton suggested an equatorial position and hence an $\alpha$-glycoside bond.
NMR spectroscopy was also used to determine the relative stereochemistry of the aglycone macrolide system of these compounds. Kobayashi et al. ${ }^{13,14}$ reported an approach for stereochemical assignment of polyketides based on universal NMR databases. They showed that stereoelectronic interactions between the structural motifs connected with $\mathrm{CH}_{2}$ bridges are significant for stereochemical assignment. Specifically, they reported that 1,3,5-trisubstituted acyclic compounds show a characteristic chemical shift that is dependent on the 1,3- and 3,5-relative configuration, but is independent of the functionalities present outside this structural motif. On this basis, the relative configuration of the C-37-C-39 position was presumed the syn/syn configuration, deduced by the significant upfield C-47 chemical shift $(\delta 5.0){ }^{4}$

To further confirm this assumption, we have determined the minimum ${ }^{13} \mathrm{C}$ NMR $\Delta \delta$ value $\left(\Delta \delta=\delta_{\mathrm{M}}-\delta_{\text {Ka-h }}\right)$ between the $\delta_{\mathrm{M}}$ of the adjusted carbons of a representative fragment of 1 and the eight possible model stereoisomers $\delta_{\text {Ka-h }}$ previously reported by Kishi, ${ }^{15}$ (Supplementary Figure S22 and Supplementary Tables S4 and S5 of the Supplementary Material). Application of this statistical approach to the C-37-C-40 tetrad, in which the contribution to the $\sum|\Delta \delta|$ of the sterocentres that support $\gamma$ and $\delta$ effects, induced by external substituents on the tetrad, were alternatively or simultaneously discounted, revealed a preferential syn/syn/anti configuration for these centers. The same statistical approach applied to the C-36-C-39 tetrad (Supplementary Figure S22 and Supplementary Tables S6 and S7 of the Supplementary Material), also indicated an anti/syn/syn configuration for these centers (shown as syn/syn/anti in Supplementary Table S7 due to the carbon numbering referring to the positions in Kishi's diasteroisomer).

As the pentad C-36-C-40 can be considered as the superposition of the two tetrad units (C-36-C-39 and C-37-C-40), the complete anti/ syn/syn/anti stereochemistry of this pentad was fully deduced. The tetrads containing C-35 and C-41 were not considered as these carbons lack free hydroxy functions. The remaining stereogenic centers of the C-34-C-41 stereocluster were assigned using ROESY NMR experiments. As proof of the suggested configuration from the Kishi NMR data set, ROESY correlations between H-36 and H-45/ $\mathrm{H}-47, \mathrm{H}-37$ and $\mathrm{H}-38 / \mathrm{H}-39, \mathrm{H}-38$ and $\mathrm{H}-46 / \mathrm{H}-48$ unambiguously established the anti/syn/syn/anti stereochemistry cited above. In addition, further ROESY correlations between H-34 and H-46, H-35 and $\mathrm{H}-36 / \mathrm{H}-45$ and $\mathrm{H}-40$ and $\mathrm{H}-47 / \mathrm{H}-41$, along with the large value of the coupling constants $J_{34-35}=9.6 \mathrm{~Hz}$ and $J_{36-37}=9.5 \mathrm{~Hz}$ yielded the relative configuration of C-34-C-41, following the same reasoning as used for elucidation of the novonestmycins ${ }^{2}$ (Figure 3 ).

Kishi's data sets were also used for the stereochemical assignment of the 1,3,5-triol structural motif (C-23-C-27). In this regard, the ${ }^{13} \mathrm{C}$ NMR chemical shift of the central C-25 $(\delta$ 68.3) atom of the C-23C-27 portion matched either a syn/anti or anti/syn configuration, ${ }^{4,16,17}$ but the ${ }^{13} \mathrm{C}$ NMR chemical shift of the C-23 ( $\delta$ 65.5) atom only matched an anti/syn configuration (Supplementary Figure S23 of the Supplementary Material). In addition, observation of a ROE correlation between $\mathrm{H}-25$ and $\mathrm{H}-27$ but not with $\mathrm{H}-23$ confirmed the relative anti/syn configuration of the structural motif C-23-C-27.

The relative stereochemistry of the tetrahydropyran ring was deduced from ROESY correlations and the small coupling constant observed between $\mathrm{H}_{\mathrm{eq}}-18$ and $\mathrm{H}-19$ as shown in Figure 3. Furthermore, ROE correlations between $\mathrm{H}-21$ and $\mathrm{H}-19 / \mathrm{H}-23$ and between $\mathrm{H}-15$ with $\mathrm{H}_{\mathrm{ax}}-18$ established the relative configuration of the C-17-C-27 fragment.

A small coupling constant between $\mathrm{H}-15$ and $\mathrm{H}-14\left(\mathrm{~J}_{14-15}=2.7 \mathrm{~Hz}\right)$ along with the ROE correlation between $\mathrm{H}-15$ and $\mathrm{H}_{\mathrm{ax}}-18$ suggested a 

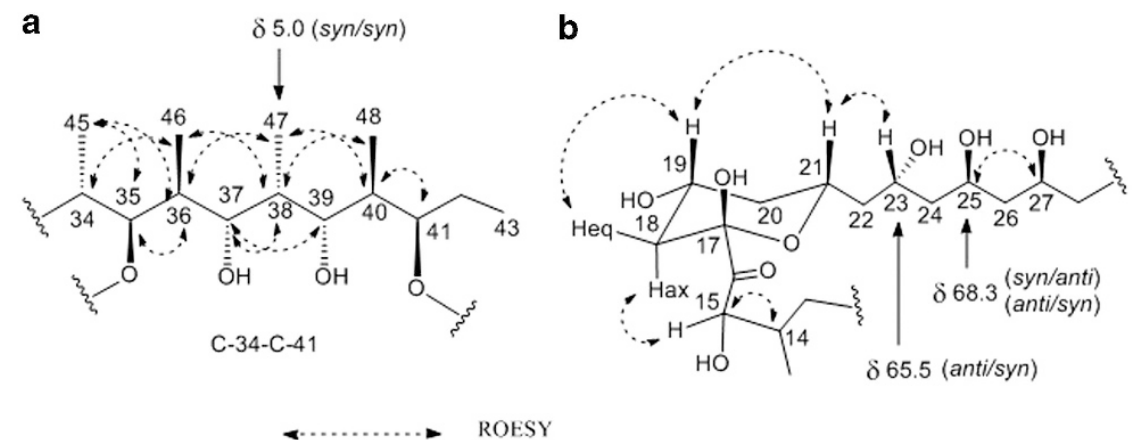

Figure 3 ROESY correlations and relative stereochemistry for the (a) C-34-C-41 and (b) C-17-C-27 portions in 1. J 18 eq-19=4.7 Hz. Representative chemical shifts are also indicated.
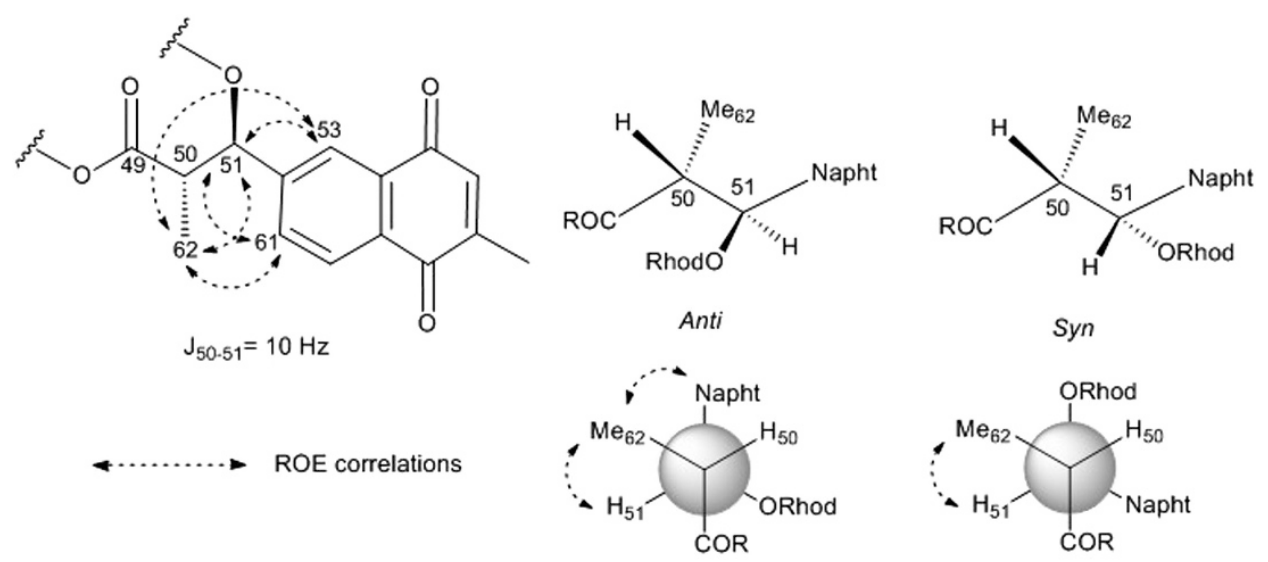

Figure 4 ROESY correlations and relative stereochemistry for the C-50-C-51 portion in 1.

syn configuration between C-14 and C-15 centers, but the absence of a cross peak between $\mathrm{H}_{\mathrm{ax}}-18$ and $\mathrm{H}-14$ in the ROE experiment (as described for novonestmycin $)^{2}$ failed to provide sufficient evidence to determine the relative stereochemistry of C-14-C-15 unit.

Finally, a large coupling constant between $\mathrm{H}-50$ and $\mathrm{H}-51$ $\left(\mathrm{J}_{50-51}=10 \mathrm{~Hz}\right)$ along with the observation of ROE correlations between $\mathrm{H}-62$ and $\mathrm{H}-51 / \mathrm{H}-53 / \mathrm{H}-61$ but not with any protons of the rhodinose sugar (Figure 4) established the relative configuration of the stereocluster C-50-C-51. The coupling constants and ROE correlations for compound $\mathbf{2}$ are entirely consistent with this compound having the same stereochemistry as compound 1. Nevertheless, the relative stereochemistry of the stereocluster C-5-C-7 remains undefined owing to insufficient quantity of the compounds to attempt degradation or derivatization assays.

In conclusion, we have determined the structures of $\mathbf{1}$ and 2 as shown in Figure 1, establishing the relative configuration of three stereocluster portions, but with the absolute stereochemistry of these compounds remaining to be determined.

\section{Biological activity}

Both PM100117 (1) and PM100118 (2) have shown potent antitumor activity and slight antifungal activity against Candida albicans ATCC10231.

To determine the cytotoxic activities of compounds 1 and 2, A549 human lung carcinoma cells, MDA-MB-231 human breast adenocarcinoma cells and HT29 human colorectal carcinoma cells were tested. Concentration of $50 \%$ inhibition on cell growth $\left(\mathrm{GI}_{50}\right)$ was calculated according to the procedure described in the literature. ${ }^{18}$ Cell survival was estimated using the National Cancer Institute algorithm. ${ }^{19}$ Three dose-response parameters were calculated for each compound. The cell proliferation assay showed strong cytotoxic activities of $\mathbf{1}$ and $\mathbf{2}$ with a $\mathrm{GI}_{50}$ values in the range 0.7-9.2 $\mu \mathrm{M}$ (Table 2). Both compounds alter the plasma membrane of tumor cells, inducing loss of membrane integrity and subsequent cell permeabilization, giving rise to a fast and dramatic necrotic cell death.

\section{DISCUSSION}

Our investigation on the metabolites from marine cultivable Streptomyces caniferus GUA-06-05-006A has resulted in the isolation of two new cytotoxic polyhydroxyl macrolide lactones PM100117 (1) and PM100118 (2). By a combination of spectroscopic methods, mainly NMR experiments, we were able to elucidate the planar structures of the aglycone and also the relative stereochemistry for the sugars of the side chain. These two compounds belong to 36-membered macrocyclic analogs, also found in Streptomyces, which have shown interesting biological properties such as fungicidal, agricultural bactericide, immunosuppressant as well as antitumor activities. Different grades of activity of these compounds could be attributed to the presence of diverse sugar units on the side chain of these macrolides. This assumption encourages us to further study the manipulation of the gene cluster responsible for $\mathbf{1}$ and $\mathbf{2}$ that would lead to modifications of the glycosylation pattern. 


\section{METHODS}

\section{General experimental procedures}

Optical rotations were determined using a Jasco P-1020 polarimeter. UV spectra were obtained with an Agilent 8453. (+)-HRESI-MS was performed on an Agilent 6230 time of flight LC/MS. NMR spectra were recorded on a Varian 'Unity $500^{\prime}$ spectrometer at $500 / 125 \mathrm{MHz}\left({ }^{1} \mathrm{H} /{ }^{13} \mathrm{C}\right)$. Chemical shifts were reported in p.p.m. using residual $\mathrm{CD}_{3} \mathrm{OD}\left(\delta 3.31\right.$ for ${ }^{1} \mathrm{H}$ and 49.0 for $\left.{ }^{13} \mathrm{C}\right)$ as internal reference. HMBC experiments were optimized for a ${ }^{3} J_{\mathrm{CH}}$ of $8 \mathrm{~Hz}$. ROESY spectra were measured with a mixing time of $350 \mathrm{~ms}$. The structures of 1 and 2 were established by ${ }^{1} \mathrm{H}$ and ${ }^{13} \mathrm{C}$ NMR and 2D NMR experiments (COSY, HMQC, HMBC).

\section{Bacterial strain}

The microbial producer Streptomyces caniferus GUA-06-05-006A was isolated by spreading the homogenized marine polychaete, Filograna sp. collected near Guadalupe Island in the Pacific Ocean, on plates of Bennett's agar medium ${ }^{20}$ supplemented with nalidixic acid $(0.02 \%)$ and cycloheximide $(0.02 \%)$. The plates were incubated at $28^{\circ} \mathrm{C}$ for 30 days.

Phylogenetic analysis of the strain based on 16S rRNA gene sequence comparisons with a database ${ }^{21,22}$ of EZ Taxon cultured microorganisms, showed a 99.92\% match with Streptomyces caniferus NBRC 15389(T) (1244/1245 base pairs).

\section{Fermentation processes}

The seed culture was developed in two scale-up steps, first in $100 \mathrm{ml}$ Erlenmeyer flasks containing $20 \mathrm{ml}$ of seed medium and then in $250 \mathrm{ml}$ Erlenmeyer flasks with $50 \mathrm{ml}$ of the same medium. The seed culture was grown on a medium containing dextrose $(0.1 \%)$, soluble starch $(2.4 \%)$, soy peptone $(0.3 \%)$, yeast extract $(0.5 \%)$, tryptone $(0.5 \%)$, soya flour $(0.5 \%)$, sodium chloride $(0.54 \%)$, potassium chloride $(0.02 \%)$, magnesium chloride $(0.24 \%)$, sodium sulfate $(0.75 \%)$ and calcium carbonate $(0.4 \%)$ in tap water. The first seed culture was inoculated with $200 \mu \mathrm{l}$ of the frozen strain and the second seed culture with $10 \%$ from the previous step. Seed cultures were grown at $28^{\circ} \mathrm{C}$ using orbital shakers for $72 \mathrm{~h}$. For production, $12.5 \mathrm{ml}$ of the seed medium was transferred into 21 Erlenmeyer flasks containing $250 \mathrm{ml}$ of fermentation medium containing yeast extract $(0.5 \%)$, soya peptone $(0.1 \%)$, dextrose $(0.5 \%)$, soya flour $(0.3 \%)$, Glucidex (Roquette, France) $(2 \%)$, sodium chloride $(0.53 \%)$, potassium chloride $(0.02 \%)$, magnesium chloride $6 . \mathrm{H}_{2} \mathrm{O}(0.24 \%)$, sodium sulfate $(0.75 \%)$, manganese sulfate $4 . \mathrm{H}_{2} \mathrm{O}(0.00076 \%)$, cobalt chloride 6. $\mathrm{H}_{2} \mathrm{O}(0.0001 \%)$, di-potassium phosphate $(0.05 \%)$ and calcium carbonate $(0.4 \%)$. The culture was grown at $28^{\circ} \mathrm{C}$ using an orbital shaker $(5 \mathrm{~cm}$ eccentricity, 220 r.p.m.) for 5 days. Sterility control plates of fermentation were done on $172 \mathrm{~B}$ modified agar medium. ${ }^{23}$

\section{Extraction and bioassay guided isolation}

The fermentation broth (51) was subjected to centrifugation, and the mycelial cake extracted with 1.621 of 2-PrOH-EtOAc 2:3 (in volume). The solvent was concentrated to give a crude extract $(4.05 \mathrm{~g})$ that was further subjected to VLC on LiChroprep RP-18 with a stepped gradient from $\mathrm{H}_{2} \mathrm{O}$ to $\mathrm{MeOH}$ and $\mathrm{CH}_{2} \mathrm{Cl}_{2}$. Compounds eluting in active fractions $\left(\mathrm{H}_{2} \mathrm{O}-\mathrm{MeOH} 2: 8,659 \mathrm{mg}\right)$ were separated using semi-preparative HPLC (C-18 Sunfire column, $10 \times 150 \mathrm{~mm}, 5 \mu \mathrm{m}$, gradient $\mathrm{H}_{2} \mathrm{O} / \mathrm{CH}_{3} \mathrm{CN}$ from 78 to $81 \%$ in $15 \mathrm{~min}$, flow rate $3.5 \mathrm{ml} \mathrm{min}^{-1}$, UV detection at $215 \mathrm{~nm}$ ). Under these conditions, fractions eluting at 8.5 and $12 \mathrm{~min}$ yielded PM100117 (3.6 mg) and PM100118 (14.7 $\mathrm{mg})$, respectively.

\section{Assay of anti-proliferative activity}

A549 (ATCC CCL-185), lung carcinoma; HT29 (ATCC HTB-38), colorectal carcinoma and MDA-MB-231 (ATCC HTB-26), breast adenocarcinoma cell lines were obtained from the ATCC. Cell lines were maintained in RPMI medium supplemented with $10 \%$ fetal calf serum (FCS), 2 mM L-glutamine and $100 \mathrm{U} \mathrm{ml}^{-1}$ penicillin and streptomycin, at $37^{\circ} \mathrm{C}$ and $5 \% \mathrm{CO}_{2}$. Triplicate cultures were incubated for $72 \mathrm{~h}$ in the presence or absence of test compounds (at 10 concentrations ranging from 10 to $0.0026 \mu \mathrm{g} \mathrm{ml}^{-1}$ ). For quantitative estimation of cytotoxicity, the colorimetric sulforhodamine B (SRB) method was used. ${ }^{24}$ Briefly, the cells were washed twice with PBS, fixed for $15 \mathrm{~min}$ in $1 \%$ glutaraldehyde solution, rinsed twice in PBS, and stained in $0.4 \%$ $\mathrm{SRB}$ solution for $30 \mathrm{~min}$ at room temperature. Cells were then rinsed several times with $1 \%$ acetic acid solution and air-dried. Sulforhodamine $B$ was then extracted in $10 \mathrm{~mm}$ trizma base solution and the absorbance measured at $490 \mathrm{~nm}$.

Using the mean \pm s.d. of triplicate cultures, a dose-response curve was automatically generated using nonlinear regression analysis. Three reference parameters were calculated (National Cancer Institute algorithm) by automatic interpolation: $\mathrm{GI}_{50}=$ compound concentration that produces $50 \%$ cell growth inhibition, as compared with control cultures; TGI = total cell growth inhibition (cytostatic effect), as compared with control cultures and $\mathrm{LC}_{50}=$ compound concentration that produces 50\% net cell killing (cytotoxic effect).

\section{Assay of primary mechanism of action}

A549 lung cancer and MDA-MB-231 breast cancer cells were exposed for $24 \mathrm{~h}$ to a $10 \mu \mathrm{M}$ concentration of $\mathbf{1}$ and $\mathbf{2}$, respectively. Representative phase contrast images of the experiment (Supplementary Figure S21 included in the Supplementary Information) with both $\mathbf{1}$ and $\mathbf{2}$ showed necrotic death with the features of plasma membrane permeabilization, including the formation of giant blebs.

\section{CONFLICT OF INTEREST}

The authors declare no conflict of interest.

\section{ACKNOWLEDGEMENTS}

We gratefully acknowledge the help of our PharmaMar colleagues, C de Eguilior and S Bueno for collecting the marine sample, A Peñalver for molecular characterization of the producer bacteria, LF García for design of biological assays, S González for performing the MS experiments and S Munt for revision of the manuscript. This work was supported by the Ministry of Economy and Competitiveness of Spain under the program INNPACTO with the project number IPT-2011-0752-900000 (Bioketido).

1 Omura, S. Macrolide Antibiotics: Chemistry, Biology, and Practice 2nd Ed. (Academic Press, Boston, MA, USA, 2002)

2 Wan, Z. et al. Novonestmycins A and B, two new 32-membered bioactive macrolides from Streptomyces phytohabitans HBERC-20821. J. Antibiot. 68, 185-190 (2015).

3 Fukai, T., Kuroda, J., Nomura, T., Uno, J. \& Akao, M. Skeletal structure of neocopiamycin B from Streptomyces hygroscopicus var. crystallogenes. J. Antibiot. 52, 340-344 (1999).

4 Helaly, S. E. et al. Langkolide, a 32-membered macrolactone antibiotic produced by Streptomyces sp. Acta 3062. J. Nat. Prod. 75, 1018-1024 (2012).

5 Mikami, Y. et al. A new antifungal macrolide component, brasilinolide B, produced by Nocardia brasiliensis. J. Antibiot. 53, 70-74 (2000).

6 Kyowa Hakko Kogyo Co., Ltd., Japan. Patent JP09100290 (1995)

7 Arcamone, F., Barbieri, W., Franceschi, G., Penco, S. \& Vigevani, A. Axenomycins. I and II. J. Am. Chem. Soc. 21, 2008-2011 (1973).

8 Kihara, T., Koshino, H., Shin, Y.-C., Yamaguchi, I. \& Isono, K. Liposidolide A, a new antifungal macrolide antibiotic. J. Antibiot. 48, 1385-1387 (1995).

9 Meng, W. \& Jin, W.Z. Structure determination of new antifungal antibiotics, polaramycins A and B. Yao Xue Xue Bao 32, 352-356 (1997).

10 Matsumoto, N. et al. Lactonamycin, a new antimicrobial antibiotic produced by Streptomyces rishiriensis MJ773-88K4. J. Antibiot. 52, 276-280 (1999).

11 Sawada, Y., Tsuno, T., Miyaki, T., Naito, T. \& Oki, T. New cirramycin-family antibiotics F-1 and F-2: selection of producer mutants, fermentation, isolation, structure elucidation and antibacterial activity. J. Antibiot. 42, 242-253 (1989).

12 Komatsu, K., Tsuda, M., Tanaka, Y., Mikami, Y. \& Kobayshi, J. Absolute stereochemistry of immunosuppresive macrolide brasilinolide $\mathrm{A}$ and its new congener brasilinolide C. J. Org. Chem. 69, 1535-1541 (2004).

13 Kobayashi, Y., Lee, J., Tezuka, K. \& Kishi, Y. Toward creation of a universal NMR database for the stereochemical assignment of acyclic compounds: the case of two contiguous propionate units. Org. Lett. 1, 2177-2180 (1999).

14 Lee, J., Kobayashi, Y., Tezuka, K. \& Kishi, Y. Toward creation of a universal NMR database for the stereochemical assignment of acyclic compounds: proof of concept. Org. Lett. 1, 2181-2184 (1999).

15 Fleury, E. et al. Advances in the universal NMR database: toward the determination of the relative configurations of large polypropionates. Eur. J. Org. Chem 2009, 4992-5001 (2009). 
16 Kobayashi, Y., Tan, C. H. \& Kishi, Y. Towards creation of a universal NMR database for sterochemical assignment: the case of 1,3,5-trisubstituted acyclic system. Helv. Chim. Acta 83, 2562-2571 (2000).

17 Kobayashi, Y., Tan, C. H. \& Kishi, Y. Stereochemical assignment of the C21-C38 portion of the desertomycin/oasomycin class of natural products by using universal NMR databases: prediction. Angew. Chem., Int. Ed. 39, 4279-4281 (2000).

18 Skehan, P. et al. New colorimetric cytotoxicity assay for anticancer-drug screening. J. Natl Cancer Inst. 82, 1107-1112 (1990).

19 Robert, H. Shoemaker. The $\mathrm{NCl} 60$ human tumor cell line anticancer drug screen. Nat. Rev. Cancer 6, 813-823 (2006).

20 Atlas, R. M. in Handbook of Microbiological Media 3rd edition 205-206 (CRC, Boca ratón, FL, USA, 2004)
$21 \mathrm{Kim}$, O. S. et al. Introducing EzTaxon-e: a prokaryotic 16S rRNA Gene sequence database with phylotypes that represent uncultured species. Int. J. Syst. Evol. Microbiol. 62, 716-721 (2012).

22 Chun, J. et al. EzTaxon: a web-based tool for the identification of prokaryotes based on $16 S$ ribosomal RNA gene sequences. Int. J. Syst. Evol. Microbiol. 57, 2259-2261 (2007).

23 Romero, F., Fernández-Chimeno, R. I., de la Fuente, J. L. \& Barredo, J. L. in Methods and Protocols (ed. Barredo, J. L.) XI, 335 (A product of Human Press, New York City, NY, USA, 2012).

24 Papazisis, K. T., Geromichalos, G. D., Dimitriadis, K. A. \& Kortsaris, A. H. Optimization of the sulforhodamine B colorimetric assay. J. Immunol. Methods 208, 151-158 (1997).

Supplementary Information accompanies the paper on The Journal of Antibiotics website (http://www.nature.com/ja) 